\title{
Wafer Preparation and lodine- Ethanol-Ethanol Passivation Procedure for Reproducible Minority-Carrier Lifetime Measurement
}

\section{Preprint}

B. Sopori, P. Rupnowski, J. Appel, V. Mehta, C. Li, and S. Johnston National Renewable Energy Laboratory

Presented at the 33rd IEEE Photovoltaic Specialists Conference San Diego, California May 11-16, 2008

Conference Paper NREL/CP-520-42574

May 2008 


\section{NOTICE}

The submitted manuscript has been offered by an employee of the Midwest Research Institute (MRI), a contractor of the US Government under Contract No. DE-AC36-99G010337. Accordingly, the US Government and MRI retain a nonexclusive royalty-free license to publish or reproduce the published form of this contribution, or allow others to do so, for US Government purposes.

This report was prepared as an account of work sponsored by an agency of the United States government. Neither the United States government nor any agency thereof, nor any of their employees, makes any warranty, express or implied, or assumes any legal liability or responsibility for the accuracy, completeness, or usefulness of any information, apparatus, product, or process disclosed, or represents that its use would not infringe privately owned rights. Reference herein to any specific commercial product, process, or service by trade name, trademark, manufacturer, or otherwise does not necessarily constitute or imply its endorsement, recommendation, or favoring by the United States government or any agency thereof. The views and opinions of authors expressed herein do not necessarily state or reflect those of the United States government or any agency thereof.

Available electronically at http://www.osti.gov/bridge

Available for a processing fee to U.S. Department of Energy and its contractors, in paper, from:

U.S. Department of Energy

Office of Scientific and Technical Information

P.O. Box 62

Oak Ridge, TN 37831-0062

phone: 865.576 .8401

fax: 865.576 .5728

email: mailto:reports@adonis.osti.gov

Available for sale to the public, in paper, from:

U.S. Department of Commerce

National Technical Information Service

5285 Port Royal Road

Springfield, VA 22161

phone: 800.553 .6847

fax: 703.605.6900

email: orders@ntis.fedworld.gov

online ordering: http://www.ntis.gov/ordering.htm 


\title{
WAFER PREPARATION AND IODINE-ETHANOL PASSIVATION PROCEDURE FOR REPRODUCIBLE MINORITY-CARRIER LIFETIME MEASUREMENT
}

\author{
Bhushan Sopori, Przemyslaw Rupnowski, Jesse Appel, Vishal Mehta, Chuan Li and Steve Johnston \\ National Renewable Energy Laboratory, 1617 Cole Blvd., Golden, CO 80401
}

\section{INTRODUCTION}

Measurement of the bulk minority carrier lifetime $\left(\mathrm{T}_{\mathrm{b}}\right)$ by optical methods, such as photocurrent decay or QSSPC, is strongly influenced by surface recombination. A number of techniques are known to lower the effective surface recombination velocity. These include use of oxidation, floating N/P junction, $\mathrm{SiN}: \mathrm{H}$ layer, HF immersion, and use of iodine in ethanol or methanol (I-E solution) [1-7]. Use of I-E appears to be very simple and this technique does not require any high temperature treatment such as oxidation, diffusion, or nitridation processes that can change $\mathrm{T}_{\mathrm{b}}$ [1]. Yet, this is not a preferred procedure within photovoltaic community because it is a common experience that it is difficult to obtain same $\mathrm{T}_{\mathrm{b}}$-values reproducibly, particularly when the wafer lifetime is long. Our objective for studying lifetime measurement using I-E passivation is twofold: (i) to apply it to compare lifetimes of wafers (having different $\mathrm{T}_{\mathrm{b}}$ ) by various techniques such as QSSPC and transient PCD using short laser pulses of different light intensity; NREL has a number of $\mathrm{T}_{\mathrm{b}}$ measurement systems; and (ii) to make minority carrier diffusion length (L) measurements by surface photovoltage technique, and to use $\mathrm{T}_{\mathrm{b}}$ and $\mathrm{L}$ data to determine diffusivity (D) values for various impurity and defect concentrations, using relationship $L^{2}=D^{*} T_{b}[3,6$, 7].

We have investigated various reasons which can make lifetime measurements irreproducible using I-E solution passivation. We studied influence of the strength of iodine in ethanol solution, wafer cleaning procedures, influence of wafer container during lifetime measurement, and stability of I-E. Although some of these studies were also performed by other researchers, they only examined individual parameters [2]. Our objective was to examine interdependencies between these parameters. We have determined that the problems in $\mathrm{T}_{\mathrm{b}}$ measurement arise from two main sources: (i) improper wafer cleaning, and (ii) instability of I-E solution when in contact with a Si wafer.

\section{INFLUENCE OF WAFER CLEANING}

Our initial cleaning procedure ("ICP") was similar to used by others, and consisted of the following: removal of organics by solvent clean followed by DI water rinse, piranha $\left(\mathrm{H}_{2} \mathrm{SO}_{4}: \mathrm{H}_{2} \mathrm{O}_{2} 2: 1\right)$ clean at $80{ }^{\circ} \mathrm{C}$, Dil. HF rinse, $\mathrm{DI}$ water rinse and nitrogen drying.

Following this cleaning by "ICP" the sample was placed in petri dish or polyethylene bag. We found that zip-lock bags provided an excellent way to passivate the sample. We tried a variety of bags of different quality and thicknesses. The most convenient is 1 mil polyethylene bag. A well cleaned sample is placed in a polyethylene bag and covered on both sides with I-E solution (typically the molarity of 0.1 ). Excess solution from each surface is squeezed out to leave a thin uniform layer of the solution on the surface. In our measurements the molarity of the solution (within range of 0.01 and 0.1 ) did not influence the measurement. Figure 1 shows typical measured lifetime using QSSPC technique using Sinton apparatus, as a function of time (curve A). The wafer was a semiconductor grade, $p$ type, with a resistivity of $12.8 \Omega-\mathrm{cm}$.

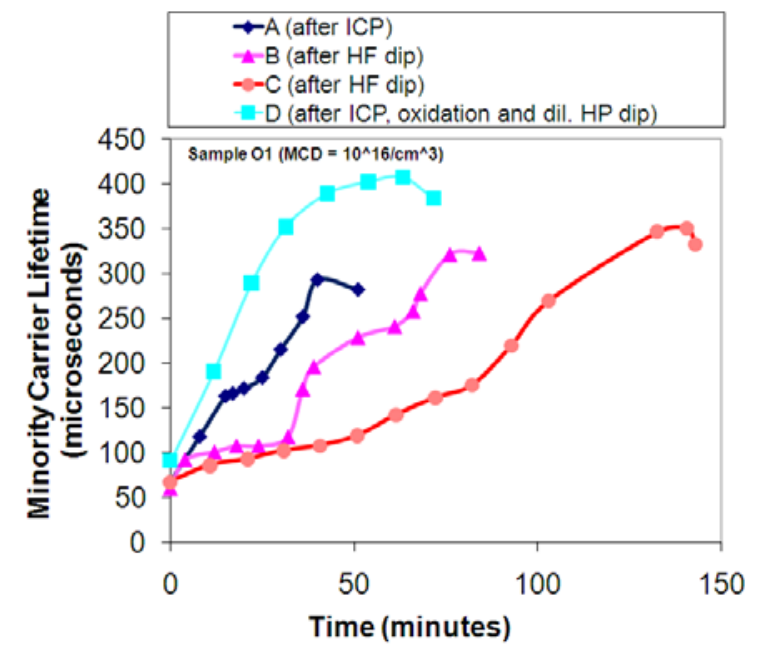

Fig. 1. $T_{B}$ of a p-type Si wafer measured by QSSPC as a function of time. The sample was cleaned by "ICP" and passivated in IE solution. (A) after ICP; (B) dil. HF dip after (A); (C) dil. HF dip after (B); (D) after oxidation clean.

The lifetime values correspond to injection level of $10^{16}$ $\mathrm{cm}^{-3}$. The wafer was prepared using above described ICP and the measurements were made every 5 minutes. Following these measurements, the sample 
was dipped in dil. HF and dried, and measured (curve $B$ ). The curve $C$ was done after dipping the sample once again following measurement $B$.

These and similar other results indicated that the sample surface was progressively loosing cleanliness resulting in longer time to reach final lifetime. This indicated that surface was not properly cleaned and that near-surface region influences the passivation characteristics of I-E/Si interface [4]. It also indicated that very thin region near the surface can have a strong influence on the passivation. To confirm this, we cleaned the wafers, oxidized a thin region at the surface, and etched the oxide off. Curve D shows the time dependence of the wafer using I-E passivation. This curve shows that the lifetime maximum was reached much faster and the maximum is higher than previous values. It is clear that it is necessary to remove the native surface (in this case by oxidation and dil. HF dip). To establish how deep the surface has to be removed, we performed oxidation in steps. Figure 2 shows the time dependence of the lifetime measurements for first three steps. The sample was cleaned and oxidized after each set of measurements. Further oxidations only increased the slope of the curves while the $\mathrm{T}_{\max }$ remained the same.

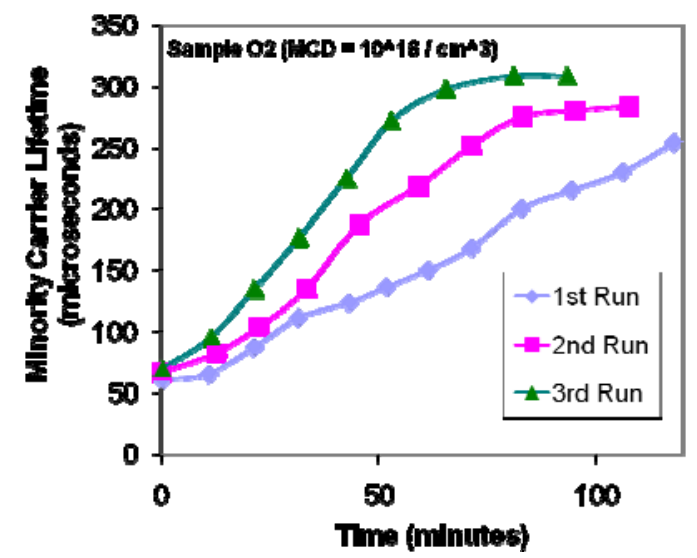

Fig. 2. Time dependence of $\mathrm{T}_{\mathrm{B}}$ after including oxidation in the cleaning procedure, for sequential cleaning steps.

\section{INFLUENCE OF ILLUMINATION}

We also observed that if the measurements were done at shorted intervals, the slope of the curves increased. This is an interesting phenomenon indicating that the I-E surface passivation has a light-activated component. To evaluate this effect, we cleaned a wafer (using our new oxidation procedure), placed in an I-E bag, and exposed it to about 0.5 sun intensity from a solar simulator for 15 minutes. It was found that the lifetime after the exposure gave the $T_{\max }$ immediately after the exposure; furthermore, there was a slow decrease (as shown in Figure 3). This decrease occurs for all wafers after the measured lifetime reaches maximum. Figure 4 shows a short-term variation of $\mathrm{T}_{\mathrm{b}}$ for a long lifetime wafer.

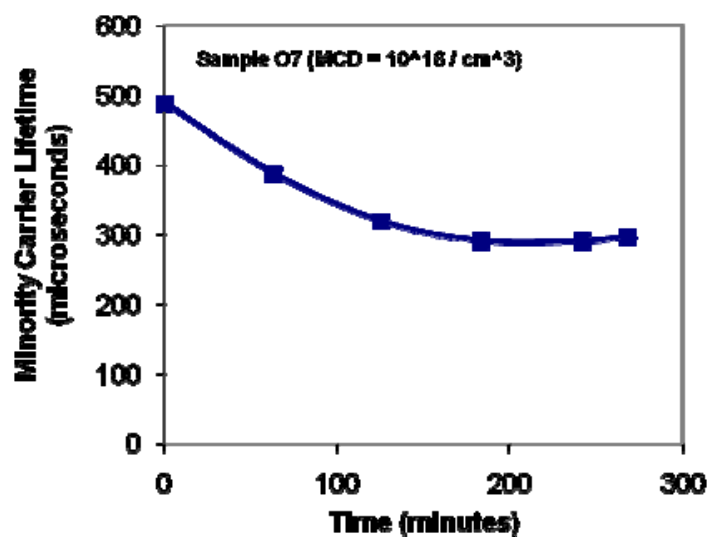

Fig. 3. $\mathrm{T}_{\mathrm{B}}$ decay after light exposure (no rise time was observed)

It was tempting to assume that light-induced passivation occurred from dissociation of I-E solution (presumably to ionize I), which might be induced by UV light. When the wafer in I-E bag was exposed to UV light, the lifetime did not reach $T_{\max }$. We also tried to determine if the effect was thermally induced because exposure of the wafer in I-E bag caused it to heat. Again heating did not produce any change in the lifetime. Figure 5 elucidates the influence of various treatments on time dependence of the lifetime measured immediately after the treatment.

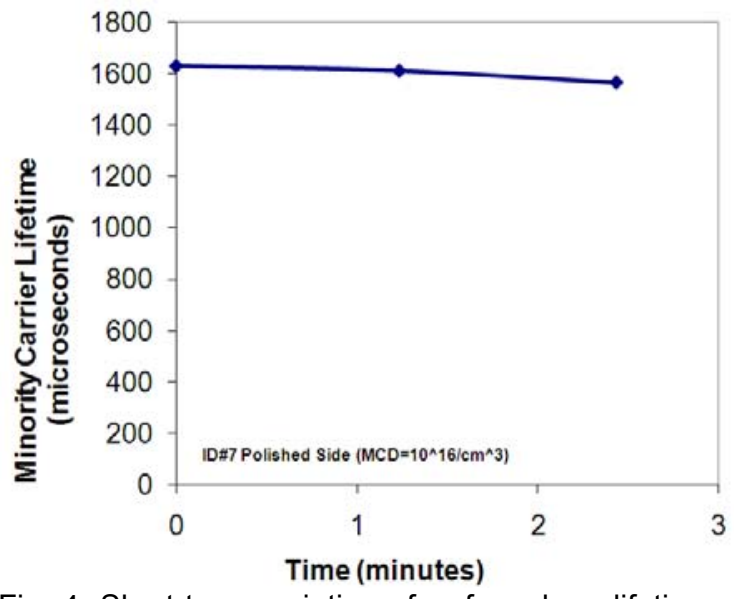

Fig. 4. Short-term variation of $\mathrm{T}_{\mathrm{B}}$ for a long lifetime wafer. The wafer was cleaned with the new procedure.

\section{DISCUSSION}

Our experiments seem to indicate that wafer preparation for a good passivation requires two essential steps:

1. Wafer cleaning, which includes removal of about 200 $-300 \AA$ of $\mathrm{Si}$ from each surface. We have outlined a procedure that yields a very clean surface. We have found that use of fresh chemicals (piranha, HF, and other acids) for each batch of wafers minimizes surface quality variations. Our experience is that these chemical have propensity to acquire impurities from ambient and, 
in some cases, leach them from the containers if very high quality containers are not used. We suggest use of optical oxidation following piranha clean. Although piranha process also produces a thin layer of a suboxide, it requires multiple steps of piranha clean to remove the desired thickness. We have noted that Kimerling et.al [2] had observed improvement in measured $\mathrm{T}_{\mathrm{b}}$ following multiple cleaning. However, they did not attribute this to surface removal. It should be noted that similar cleaning is also demanded for obtaining high quality oxide or nitride passivation. In this regard, wafer preparation for I-E passivation is similar.

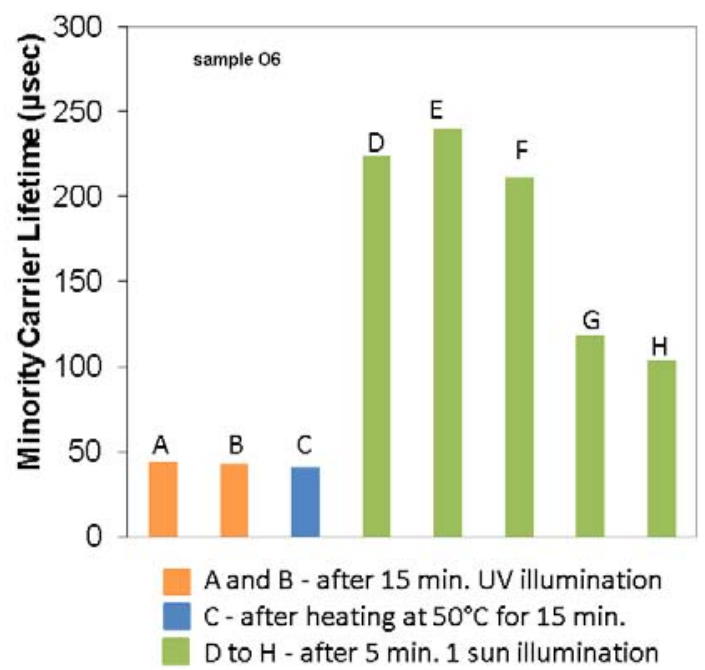

Fig. 5. $\mathrm{T}_{\mathrm{B}}$ of a p-type wafer, resistivity $27 \Omega-\mathrm{cm}$ measured after several treatments: UV for $15 \mathrm{~min}$ and $30 \mathrm{~min}$, heating, exposure to light for different times.

2. Activation of surface passivation, which seems to require establishment of a steady state between I-E solution and $\mathrm{Si}$ surface. One can expect two mechanisms to participate in this process: (a) formation of a steady state at the I-E and Si interface in which $\mathrm{I}^{-}$ ions produce a surface field. This field is influenced by the parameters (such as resistivity and lifetime) of the Si wafers. It is expected that a surface layer of the order of a Debye length plays an important role. Because a wafer typically has a contamination at the surface layer, which may extend to a $200-300 \AA$, it is necessary to remove this layer to create a high quality passivation. This mechanism can also explain sensitivity of passivation to the light and perhaps dependence on resistivity and lifetime. Unfortunately, our data on a variety of wafers are not consistent. For example, wafers from a lot (with similar resistivities and lifetime) do not have same dependence of lifetime on the light exposure. However, we consistently see that lower lifetime wafers have less dependence on the light exposure (i.e. they stabilize faster). Further investigations are being done to understand the observed time dependence of the measured lifetime time.
Based on these results, we can propose a simple model for wafer preparation as shown in Figure 6. (a)

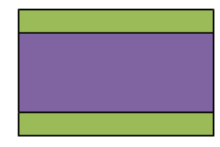

(b)

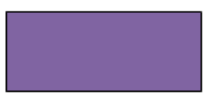

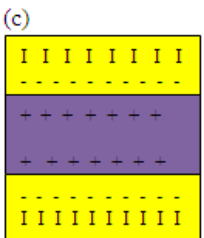

Fig. 6. A wafer with a shallow (200-300 Å) contaminated surface layer (a), after cleaning (b) and surface passivation (c).

\section{ACKNOWLEDGMENTS}

This work was supported by the U.S. Department of Energy under Contract No. DE-AC36-99G010337 with the National Renewable Energy Laboratory.

\section{REFERENCES}

[1] Horanyi, T.S. et. al. In situ bulk lifetime measurement on silicon with a chemically passivated surface. Applied Surface Science, 63 (1993) 306-311

[2]. M'saad, Hichem et. al. Monitoring and Optimization of Silicon Surface Quality. Journal of the Electrochemical Society, Vol. 142, No. 8 August 1995

[3] Palais, O. et. al. Contactless mapping of lifetime and diffusion length scan map of minority carriers in silicon wafers. The European Physical Journal: Applied Physics, 10, 157-162 (2000)

[4] Royea, William J. et. al. Role of inversion layer formation in producing low effective surface recombination velocities at Si/liquid contacts. Applied Physics Letters, Volume 77, Number 16, 16 October 2000

[5] Macdonald, D.H. et. al. Iron detection in crystalline silicon by carrier lifetime measurements for arbitrary injection and doping. Journal of Applied Physics, Volume 95, Number 3, 1 February 2004

[6] Bail, M. and R. Brendel. Separation of Bulk and Surface Recombination By Steady State Photo Conductance Measurements. 16th European Photovoltaic Solar Energy Conference, 1-5 May 2000, Glasgow, UK

[7] Buczkowski, A. et. al. Photoconductance Minority Carrier Lifetime vs. Surface Photovoltage Diffusion Length In Silicon. Journal of the Electrochemical Society, Vol. 140, No. 11, November 1993 


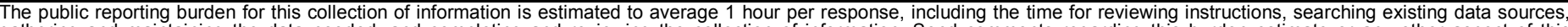

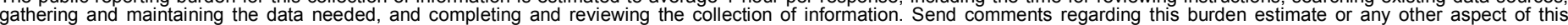

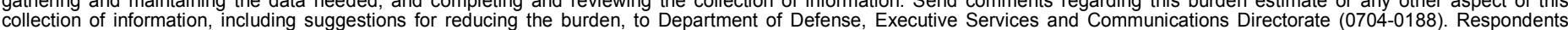

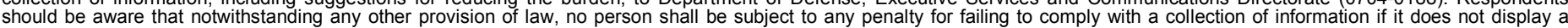

currently valid OMB control number.

PLEASE DO NOT RETURN YOUR FORM TO THE ABOVE ORGANIZATION.

\begin{tabular}{ll|l} 
1. & $\begin{array}{l}\text { REPORT DATE (DD-MM-YYYY) } \\
\text { May } 2008\end{array}$ & $\begin{array}{l}\text { 2. } \\
\text { REPORT TYPE } \\
\text { Conference Paper }\end{array}$ \\
\hline 4. & $\begin{array}{l}\text { TITLE AND SUBTITLE } \\
\text { Wafer Preparation and lodine-Ethanol-Ethanol Passivation }\end{array}$ \\
& $\begin{array}{l}\text { Procedure for Reproducible Minority-Carrier Lifetime Measurement: } \\
\text { Preprint }\end{array}$
\end{tabular}

6. AUTHOR(S)

B. Sopori, P. Rupnowski, J. Appel, V. Mehta, C. Li, and S. Johnston

3. DATES COVERED (From - To)

11-16 May 2008

5a. CONTRACT NUMBER

DE-AC36-99-G010337

5b. GRANT NUMBER

5c. PROGRAM ELEMENT NUMBER

5d. PROJECT NUMBER

NREL/CP-520-42574

5e. TASK NUMBER

PVA73101

5f. WORK UNIT NUMBER

7. PERFORMING ORGANIZATION NAME(S) AND ADDRESS(ES)

National Renewable Energy Laboratory

1617 Cole Blvd.

Golden, CO 80401-3393

9. SPONSORING/MONITORING AGENCY NAME(S) AND ADDRESS(ES)
8. PERFORMING ORGANIZATION

REPORT NUMBER

NREL/CP-520-42574

10. SPONSOR/MONITOR'S ACRONYM(S) NREL

11. SPONSORING/MONITORING AGENCY REPORT NUMBER

\section{DISTRIBUTION AVAILABILITY STATEMENT}

National Technical Information Service

U.S. Department of Commerce

5285 Port Royal Road

Springfield, VA 22161

13. SUPPLEMENTARY NOTES

14. ABSTRACT (Maximum 200 Words)

Measurement of the bulk minority carrier lifetime (Tb) by optical methods, such as photocurrent decay or QSSPC, is strongly influenced by surface recombination. A number of techniques are known to lower the effective surface recombination velocity. These include use of oxidation, floating N/P junction, SiN:H layer, HF immersion, and use of iodine in ethanol or methanol (I-E solution). Use of I-E appears to be very simple and this technique does not require any high temperature treatment such as oxidation, diffusion, or nitridation processes that can change tb.Yet, this is not a preferred procedure within photovoltaic community because it is a common experience that it is difficult to obtain same tb-values reproducibly, particularly when the wafer lifetime is long. Our objective for studying lifetime measurement using I-E passivation is twofold: (i) to apply it to compare lifetimes of wafers (having different tb) by various techniques such as QSSPC and transient PCD using short laser pulses of different light intensity; NREL has a number of Tb measurement systems; and (ii) to make minority carrier diffusion length (L) measurements by surface photovoltage technique, and to use $\mathrm{Tb}$ and $\mathrm{L}$ data to determine diffusivity $(\mathrm{D})$ values for various impurity and defect concentrations, using relationship $\mathrm{L} 2=\mathrm{D}^{*} \mathrm{~Tb}$.

\section{SUBJECT TERMS}

PV; minority-carrier lifetime; photocurrent; iodine-ethanol solution; initial cleaning procedure; wafer preparation;

\begin{tabular}{l}
\hline \multicolumn{3}{|l|}{ 16. SECURITY CLASSIFICATION OF: } \\
\hline \begin{tabular}{l|l|l|} 
a. REPORT & b. ABSTRACT & c. THIS PAGE \\
Unclassified & Unclassified & Unclassified \\
& & \\
\hline
\end{tabular}
\end{tabular}

\begin{tabular}{l|l|}
$\begin{array}{l}\text { 17. LIMITATION } \\
\text { OF ABSTRACT }\end{array}$ & $\begin{array}{l}\text { NO. } \\
\text { OF PABER } \\
\text { UL }\end{array}$ \\
\end{tabular}

19a. NAME OF RESPONSIBLE PERSON

19b. TELEPHONE NUMBER (Include area code) 